\title{
LA INFLUENCIA KANTIANA Y SU CRITICA EN EL PRAGMATISMO DE PEIRCE
}

\author{
Jorge R. De Miguel \\ Univ. Nacional de Rosario
}

\section{I - Peirce y el criticismo kantiano}

Cuando al comenzar su "Lección sobre Kant", en 1865, Charles S. Peirce expresaba que "existe una relación muy íntima entre la cuestión de la lógica de la ciencia, a saber, cómo puede ser válida la inferencia material, y una de las cuestiones fundamentales de la metafísica, cómo pueden ser válidas las concepciones de causa, sustancia, necesidad, etc." (1) estaba enunciando una de las preocupaciones fundamentales que determinarían el curso posterior de su pensamiento. Su filosofía pragmática sería, en definitiva, un nuevo intento de justificación del saber científico y, a partir de ella, una indagación de los alcances del conocimiento mismo. Este programa lo insertaba en la discusión gnoseológica moderna, a la que Peirce supo dar un giro particular, menos reconocido por sus contemporáneos que por la posteridad.

Aquella cuestión había sido examinada por los empiristas ingleses, la escuela escocesa del sentido común y por Kant. La opi-

\footnotetext{
(1) Peirce, C.S., “Lección sobre Kant" (TR), El Hombre, un Signo (El pragmatismo de Peirce). trad. José Vericat. Barcelona. Crítica. 1988. p. 39. En adelante. las obras de Peirce citadas corresponden a esta recopilación. Para facilitar la referencia se tomará en cuenta. en algunos casos, el título dado por los recopiladores y no el original, con la aclaración entre paréntesis "TR" en la primera vez.
} 
nión del fundador del pragmatismo era que el criticismo kantiano había sido el más exitoso en la lucha contra el dogmatismo racionalista, porque presentó a la lógica como fundamento de toda metafísica y desde ella se abocó a un análisis de la experiencia. Para Peirce, el conocimiento científico y, por ende, la metafísica, sólo puede encontrar raíces firmes en una teoría de la lógica, tal como Aristóteles y Kant io intentaron. ${ }^{(2)}$ Por lo tanto, el pragmatismo necesitaba, a juicio de Peirce, un recurso al kantismo pero, a la vez, una crítica superadora de él. Esto lo diferenciaba de otras vertientes pragmáticas de su época, más tributarias del empirismo humeano, del positivismo y de la escuela escocesa. Sin embargo, las interpretaciones más difundidas del fundador del pragmatismo han exaltado los aspectos radicalmente empiristas y anti-kantianos de su obra. Indudablemente, ha sido mérito de Apel la revisión de esta corriente, remarcando la transformación semiótica de la teoría del conocimiento operada por Peirce, a la cual entiende como una modernización del criticismo kantiano. ${ }^{(3)}$ A partir de allí, fue posible avanzar hacia una comprensión más plena de la filosofía pragmatista originaria y de sus múltiples puntos de conexión con la teoría crítica.

(2) Peirce, C.S.. "Lección sobre Kant". pp. 39 y 44 ; "Tópicos vitalmente importantes" (TR), p. 311 ; “ ¿Por qué estudiar lógica ?” (TR). pp. 334. 364 y 385. Kant hace explicita esta intención en el Prefacio de la $2 \mathrm{a}$. edición de la primera Crítica. afirmando que la lógica formal, como "propedéutica”. constituye el "vestíbulo de las ciencias". (KANT. I. Critica de la Razón Pura, trad. Manuel García Morente. Madrid. Lib. Victoriano Suárez. 1960. 2a. ed.. T. I. p. 19).

(3) Al respecto, ver Apel, Karl-Otto. ('harles S. Peirce: From Pragmatism to Pragmaticism. trad. John M. Krois. Amherst. Univ. of Massachusetts Press. 1981: "De Kant a Peirce: la transformación semiótica de la lógica trascendental“. La Transformación de la Filosofia. T. II. trad. A. Cortina. J. Chamorro y J. Conill, Madrid. Taurus. 1985. pp. 149-168. Una interesante clarificación de las tesis apelianas puede consultarse en Christensen, Carleton B., "Peirce's Transformation of Kant". Review of Metaphysics, XLVIII: 1. September 1994. pp. 91 y ss. 
Ya desde muy joven se manifestó en Peirce su admiración por la obra kantiana, en especial, la Crítica de la Razón Pura $(C R P)$, libro central en su formación intelectual, lo cual permite adscribirlo al vasto movimiento de revalorización del maestro de Koenigsberg, luego de la revisión idealista. El propio Peirce se quejaba de la incomprensión de algunos de sus aspectos fundamentales, debida a los enfoques tradicionales de Thomas Carlyle y Victor Cousin. ${ }^{(4)}$ Su punto de vista sobre la $C R P$ destacaba en ella una doble finalidad: en primer lugar, mostrar que concepciones como las de causa, sustancia, etc., "son válidas hasta cierto punto" y, en segundo lugar, "que no son válidas más allá de este punto". Si bien la "parte destructiva" había hecho una tarea demoledora del dogmatismo, Peirce sostenía que la "parte constructiva", inicialmente contrapuesta a Hume, contenía "el argumento más fuerte que nunca se haya dado antes contra el positivismo" de Comte y Mill. ${ }^{(5)}$ Por tanto, era imperioso entender que la crítica de la doctrina trascendental debía ser la premisa de toda filosofía de raigambre positivista en sentido lato, es decir, de todo análisis del conocimiento fundado en la experiencia. En pocas palabras, la pretensión de Peirce era la siguiente: la lógica es el cimiento del edificio del saber científico, pero dichos cimientos deben establecerse sobre un terreno sólido. Los aspectos formales de las proposiciones y de los argumentos, que permiten distinguir la verdad y falsedad de ellos, requieren una doctrina que le anteceda acerca de "las condiciones generales a las que tiene que conformarse el pensamiento, o los signos de cualquier tipo, con vistas a afirmar algo". Kant había sido el primero,

\footnotetext{
(4) Peirce, C.S.. “Lección sobre Kant”, pp. 40/41.

(5) Ibídem, pp. 43/44.
} 
decía Peirce, en elevar estas cuestiones a un rango prominente. ${ }^{(6)} \mathrm{Su}$ interés sobre la $C R P$ se centraba, pues, en la Lógica trascendental, en especial, en la Analítica y su antecedente en la Estética trascendental, esto es, en la manera en que Kant demostraba la validez y aplicabilidad de las categorías a objetos posibles de los sentidos. ${ }^{(7)}$ La construcción crítica de Peirce, destinada a rechazar la trascendentalidadde los elementos formales del pensamiento, deseaba replantear la problemática kantiana sobre los juicios sintéticos a priori, volviendo a una cuestión anterior: cómo son posibles en general los juicios sintéticos. ${ }^{(8)}$

\section{II - Realidad y pensamiento}

Antes de que se hubieran formado en su pensamiento las tesis centrales del pragmatismo, Peirce mostraba ya ciertas pautas sobre las raíces de su filosofía, entre las cuales, la interpretación de Kant jugaba un papel decisivo. En 1871, en ocasión de comentar la edición de A.C. Fraser de las obras de George Berkeley ${ }^{(9)}$, Peirce realizó un claro alegato en favor del realismo filosófico. En su punto de vista, ser realista no significaba aceptar que lo real son las cosas exteriores a la mente, que por ello mismo son independientes de nuestro pensamiento. Más bien, lo que Peirce rescataba era la fórmula de Duns Scoto: la existencia externa de las cosas y su representación en la mente es una y la misma realidad, que es universal en el pensamiento y singular "in re". La diferencia es sólo formal, en el modo de estar la cosa concebida, y no de naturaleza.

\footnotetext{
(6) Peirce, C.S., “¿Por qué estudiar lógica?”. p. 386.

(7) Peirce, C.S., "Lección sobre Kant”. p. 44.

(8) Ibídem, pp. 47/48.

(9) Peirce, C.S.. "Las obras de George Berkeley", (TR). pp. 63 y ss.: v. también "Algunas consecuencias de cuatro incapacidades", p. 119.
} 
Para Peirce, el realista no ve a la mente como un receptáculo, de manera que si una cosa está dentro deja de estar afuera, sino que "sostendrá que los mismos objetos que, en la experiencia, están inmediatamente presentes en nuestras mentes, existen realmente tal como se experimentan fuera de la mente", por lo que, "en un juicio verdadero el objeto inmediato del pensamiento es la realidad". Si así no fuera, se perdería todo control sobre el conocimiento, pues al conceptualizar, "no estaríamos conociendo nada sobre las cosas, sino sólo de nuestros propios pensamientos, y nuestra opinión no se convertiría de verdadera en falsa por un cambio de las cosas".

Peirce pensaba que la doctrina scotista constituía el corolario metafísico natural de toda práctica científica. Sin embargo, el hecho de que su rival, el nominalismo de Ockham. hubiera sido el que proveyera las bases filosóficas a la ciencia moderna, a su juicio, se debía más que a un examen riguroso de las obras escolásticas, a cuestiones de índole política. Calificaba al pensamiento ockhamista de "esencialmente anticientífico", pues los universales quedaban reducidos a un signo lógico mental con el cual se conceptualizaban las singularidades, y la realidad, situada por completo fuera de la mente, sólo era la causa de las sensaciones, sin que pueda resolverse la validez objetiva del pensamiento. No obstante las dificultades para dar fundamento lógico al conocimiento científico por esta vía, la filosofía empirista inglesa, de Hobbes a Hume, había hecho suya, con leves variantes, la teoría de Ockham. ${ }^{(10)}$ Recién fue Kant quien, con un fenomenalismo distinto del de Hume, colocó la cuestión en sus justos términos. La inversión copernicana representaba para Peirce "el tránsito del punto de vista nominalista de la realidad al

\footnotetext{
(10) Peirce, C.S.. “_Por qué estudiar lógica?”. pp. 363/64: “Las obras de (3.Berkeley”, pp. 71 a 74 y 79 .
} 
realista" pues, en esencia, esta nueva filosofía consideraba "el objeto real como determinado por la mente", con lo cual, conceptos e intuiciones alcanzaban validez objetiva y, entonces, la realidad dejaba de ser una causa incognoscible de la acción mental para aparecer como el "producto normal" de ella. (11) En suma, Peirce partía del realismo scotista como fundamento racional de la ciencia moderna y atribuía a Kant haber reconocido esta cuestión, desarrollando así su crítica a la gnoseología cartesiana e inglesa.

Sobre estas coincidencias con el kantismo, Peirce elaboraba una visión de la realidad y del papel del pensamiento en ella que ya mostraba diferencias en varios aspectos con el planteo de la CRP. La noción de realidad era, para Peirce, concerniente a la lógica, porque su concepto no podría ser alcanzado sino por referencia a las condiciones del pensar. A diferencia de la ficción, mero producto de la imaginación, que tiene las características de quien la piensa, lo real es aquéllo cuyos caracteres "son independientes de lo que cualquiera puede pensar que son". Pero esa independencia no está tomada, como en el realismo clásico, respecto de todo pensamiento, sino sólo del de los individuos particulares. o bien, de un número finito de hombres. La realidad, sin embargo, no es independiente del pensamiento en general. ${ }^{(12)}$ Nuestra opinión particular contiene siempre errores; hay elementos accidentales y arbitrarios como las circunstanciasy las inclinaciones, que influyen en ella. Pero, afirmaba Peirce, si logramos adquirir la suficiente información y ejercitamos debidamente el pensamiento sobre una determinada cuestión, alcanzaremos una conclusión igual a la que podrían lograr otras mentes bajo las mismas condiciones. Es decir, "a

\footnotetext{
(11) Peirce, C.S.. "Las obras de G.Berkeley.". pp. 67/68.

(12) Peirce, C.S.. "Cómo esclarecer nuestras ideas". pp. 218 y 221.
} 
la larga, la opinión humana tiende universalmente a una forma definida, que es la verdad". Esta opinión final no es, pues, independiente del pensamiento en general, sino de aquéllo que es arbitrario e individual en el pensar particular. En consecuencia, lo real es "lo que en la opinión final se piensa que existe, y nada más", o sea, que su independencia es sólo con referencia a "cómo podamos sentir o pensar sobre ello". Así, la blancura es tan real como una cosa blanca; existe en virtud del pensamiento que la conoce, pero no uno arbitrario o accidental, para el cual dicha blancura pudiera ser negrura, "sino uno que persiste en la opinión final". (13) El realismo de Peirce rechazaba la idea de una cosa en sí misma, pero a su vez, ello no impedía "considerar las apariencias de los sentidos como únicos signos de la realidad". Sólo que "detrás" de las sensaciones, no admitía la presencia de una realidad subsistente por sí, "causa incognoscible" de aquéllas. O sea, los sentidos nos representan la realidad pero, su información, las sensaciones, se origina en los conceptos inteligibles producidos por la acción mental que aquéllos movilizan. ${ }^{(1+)}$

Consideremos un poco más detenidamente este planteo peirciano en aquellos "extremos" en los cuales pensamiento y realidad parecen coincidir: el origen y el destino final del conocimiento. Las cosas reales producen "efectos sensibles específicos" en nuestra mente, generan "cogniciones" que se derivan lógicamente entre ellas, haciéndose cada vez más generales y distintas. Ahora bien, dichas cogniciones son verdaderas y no-verdaderas según sus objetos sean reales o irreales. ¿Cómo distinguirlas? Peirce descartaba que ello pudiera hacerse sobre la base de la certeza individual del

(13) Peirce, C.S.. "Las obras de (i.Berkeley”, pp. 65 a 67.

(1+) Ibídem, p. 66. 
yo cartesiano o del esquema racional del sujeto trascendental kantiano. Su respuesta se dirigía a exaltar la validez intersubjetiva del conocimiento: lo real es lo que surge de despejar las cogniciones de enunciados particulares, que el capricho de uno o varios de nosotros ha puesto en ellas. Ese proceso remite a un juez: la comunidad. Es real lo que, en "un tiempo suficientemente futuro", la comunidad piensa y razona como tal. Es posible que, aún en tales condiciones, la comunidad crea verdadero lo que es falso. Si el error es absolutamente incognoscible, en verdad no hay error alguno. La consecuencia, sostenía Peirce, es que nada impide que conozcamos las cosas exteriores tal cual son y, probablemente, las conozcamos en muchos casos, "aún cuando nunca podamos estar absolutamente seguros de conseguirlo en cualquier caso específico". (15)

Por consiguiente, tanto en su origen como en su destino último, el conocimiento es una relación comunitaria. La lógica relacional que lo conduce responde a la naturaleza de la realidad misma. Nuestra primera información sensible está determinada por una cognición previa: aquélla que nos permite distinguirlo real de lo irreal. Pero, alejándose de un esquema platonizante, Peirce sostenía que dicha cognición sólo establecía una distinción lógica entre un ente relativo a mis determinaciones privadas y un ente "tal como sería a la larga", libre de mis antojos. ${ }^{(16)}$ En suma, el conocimiento comienza cuando el hombre descubre la distancia entre su yo y la comunidad y admite que es ésta la que le otorga valor a sus cogniciones.

(15) Peirce, C.S., “Algunas consecuencias de cuatro incapacidades”. pp. 118/19; “'Cómo esclarecer nuestras ideas", pp. 218/19; "La fijación de la creencia”, pp. 194/95.

(16) Peirce, C.S.. “Algunas consecuencias de cuatro incapacidades”. pp. 118 y 121. 
Peirce no hacía distinción entre ciencia y filosofia cuando atribuía carácter comunitario al proceso del conocimiento. Una de sus críticas al cartesianismo se dirigía al postulado que convierte a individuos singulares en jueces absolutos de la verdad. Anticipándose a doctrinas epistemológicascontemporáneas, Peirce exaltaba el consenso de los investigadores como prueba de las teorías y como aval de la cientificidad misma de las ramas del saber, cuando el acuerdo se extiende a los principios fundamentales. ${ }^{(17)}$ Así describía el procedimiento de investigación:

"Mentes diferentes pueden partir con los más antagónicos puntos de vista, pero el progreso de la investigación, por una fuerza exterior a las mismas, las lleva a la misma y única conclusión. Esta actividad del pensamiento que nos lleva, no donde deseamos, sino a un fin preor-denado, es como la operación del destino. Ninguna modificación del punto de vista adoptado, ninguna selección de otros hechos de estudio, ni tampoco ninguna propensión natural de la mente, pueden posibilitar que un hombre escape a la opinión predestinada. Esta enorme esperanza se encarna en el concepto de verdad y realidad. La opinión destinada a que todos los que investigan estén por último de acuerdo en ella es lo que significamos por verdad, y el objeto representadoen esta opinión es lo real". (subr. nuestro) ${ }^{(18)}$

La visión de Peirce se refería al conocimiento como un proceso que no depende de la voluntad de los investigadores ni de su genio, en última instancia. No significa tampoco que una voluntad superior los guía, sino que la necesidad lógica implícita en la rela-

(17) Ibidem, p. 89: “¿Por qué estudiar lógica?”, p. 362.

(18) Peirce, C.S., "Cómo esclarecer nuestras ideas", pp. 220/21. 
ción cognoscitiva conduce a diversas generaciones de hombres pensantes. Dicho curso requiere una esencial continuidad. Por eso, Peirce proponía comprender a la ciencia por su historia lógica y no, si cabe la expresión, por su historia social. Nada más lejano a su manera de pensar que las "rupturas epistemológicas", rotundas transformacionesde teorías vigentes que son reemplazadas por otras nuevas. En cambio, sugería dedicarle atención a aquéllo que se conserva de las viejas hipótesis. ${ }^{(19)}$ Se colige que en ellas residen "partículas" de verdad, capaces de permitir la derivación posterior hacia teorías más evolucionadas. Peirce estaba tan convencido de que el conocimiento constituye un proceso autosostenido, que afirmaba que el "acuerdo católico final", la verdad, podía extenderse mas allá de la raza humana, "a la entera comunión de mentes a la que pertenecemos", aunque sus sentidos fueran diferentes a los nuestros. ${ }^{(20)}$ Un hilo común une esta esperanza en la verdad con la necesidad de la razón pura de pensar las ideas de Dios o la Inmortalidad, en el plano teórico, o la paz perpetua, en el comportamiento práctico. En cierto modo, ellas obran desde el futuro sobre nuestro presente. También cabría incorporar a Peirce a lo que Ortega y Gasset llamaba "culturalismo" moderno, del cual Kant era un símbolo: la idea de que la vida por sí es indiferente y sólo se hace valiosa como instrumento y substrato de un "más allá" cultural.(21)

El recurso de Peirce a la comunidad como una instancia donde lo real se concreta para nosotros, es reveladora de una toma de posición implícita frente al kantismo. Ya se ha señalado la coincidencia de que la sensibilidad nos provee una primera aproximación

\footnotetext{
(19) Peirce, C.S... ¿¿Por qué estudiar lógica?”. p. 347.

(201) Peirce, C.S.. "Las obras de G.Berkeley". p. 67.

(21) Ortega y Gasset, José. El tema de nuestro tiempo. 14a. ed., Madrid. Espasa-Calpe. 1980. p. 66.
} 
al objeto. Pero a partir de allí, la necesidad de Peirce de superar la estructura trascendental del conocer, lo obliga, en lo "externo", a desmantelar todo aspecto no relativo a la mente, la cosa en sí, y en lo "interno", a buscar la garantía de nuestras cogniciones en una transubjetividad, la comunidad. Pero como Peirce deseaba eliminar toda distinción exterior-interior, la comunidad aparece como garantía de todo el conocimiento, es decir, de todos sus "elementos": objeto, sujeto y representación. El dato sensible individual, la representación particular de un yo particular, está destinada a sucumbir ante el consenso comunitario. En este sentido, Peirce transitaba un cauce hegeliano, lo cual no puede sorprendernos, ya que él mismo reconocía que "el punto más fuerte del hegelianismo es el carácter puramente impersonal que atribuye a la unidad de apercepción".(22)

Peirce consideraba al pensamiento y a la realidad como partícipes de un mismo proceso, esencialmente continuo, que tiende a borrar las diferencias: una generalización constante hasta alcanzar el acuerdo final, la verdad, el momento de máxima universalidad, donde cada particular podrá ser subsumido totalmente. De este planteo cognoscitivo se deriva una visión antropológica y ética de raíz hegeliana, que encuentra expresión elocuente en una nota insertada en uno de sus más importantes escritos:

"Cuando estudiemos el importante principio de la continuidad y veamos que todo fluye, y que cada punto participa directamente del ser de todos los demás, quedará patente que individualismoy falsedad son una misma y única cosa. Entre tanto, sabemos que el hombre no está completo en la medida en que es un individuo, que esencialmente él es un miembro posible de la

(22) Peirce, C.S., "Icono. Index y Símbolo”. (TR). p. 142. 
sociedad. Especialmente, la experiencia de un hombre no es nada si se da aisladamente. Si ve lo que otros no pueden ver, lo llamamos alucinación. Aquéllo en lo que hay que pensar no es en 'mi' experiencia, sino en 'nuestra' experiencia, y este 'nosotros' tiene posibilidades indefinidas". (subr.nuestro) ${ }^{(2.3)}$

No correspondería decir que en Kant la dimensión comunitaria está ausente. Si hien en la CRP la unidad trascendental de apercepción, siendo el aspecto universal de nuestra subjetividad cognoscente, no sostendría la experiencia de un yo particular con total prescindencia de los demás, es en la Crítica del Juicio donde se expone con mayor claridad aquella dimensión. Allí Kant afirmaba que el juicio estético se funda en un principio subjetivo de validez general, el "sentido común", "efecto del libre juego de nuestras facultades cognoscitivas", una especie de norma ideal que exige que todos "deben coincidir" con nuestro juicio. Agregaba además, que el sentido común es el presupuesto de la comunicabilidad universal de nuestro conocimiento, por lo cual aparece como condición necesaria en toda lógica y en todo principio cognoscitivo no escéptico. ${ }^{(24)}$ Hannah Arendt ha puesto de relieve con lucidez la potencialidad política del juicio estético de la tercera Crítica, justamente por su apelación al consenso de la comunidad y a la necesidad de persuadir, pensando desde el punto de vista de los otros. ${ }^{(25)}$

(23) Peirce, C.S.. "Cómo esclarecer nuestras ideas". nota 6, p. 211.

(24) Kant, I.. The Critique of Judgement. \# 20 a 22. trad. James Creed Meredith. Great Books of the Western World. Robert M. Hutchins. ed.. Vol. 42. Chicago. Enc. Britannica. 1987. pp. 492/93.

(25) Arendt, Hannah, Lectures on Kant's Political Philosophy. Chicago. The Univ. of Chicago Press. 1982, en esp. 13a. Sesión. pp. 72 y ss.: V. además su "La crisis en la cultura: su significación social y política“. trad. Ernesto Funes. Agora. 3. Invierno 1995. pp. 183 a 187. 
Jorge Dotti, por su parte, entiende que "juzgar reflexivamente es una actividad condicionada por el contexto cultural y social en que está inscripta, sólo que de una manera especial", puesto que no se somete acríticamente, sino que también es capaz de romper con lo habitualmente aceptado e instaurar hipótesis revolucionarias. ${ }^{(26)}$

Pero lo que Kant admitía como un requisito para una circulación racional de los conocimientosno es, en modo alguno, condición de su validez objetiva, algo que se asegura con el ordenamiento lógicotrascendental presente en cada mente. La visión kantiana aparejaba una estructura abierta del pensamiento, pero con conciencia plena de sus límites: hay una porción de la realidad que es inaccesible. Para Peirce, en el "largo plazo" el absoluto se desplegará, lo que hará coincidir ser y pensar. Acaso pueda resumirse ello con una leve modificación de la famosa fórmula del idealismo absoluto de Hegel: "lo que es real será racional, y lo que es racional será real", aunque sin la connotación dialéctica que ello implicaba. Es decir, según Peirce, pensamiento y realidad tienen sólo una existencia potencial, dependiente de la decisión última de la comunidad ${ }^{(27)}$, mientras que para Kant, la vida futura es un supuesto regulativo de nuestra realización moral actual exigido por la misma razón, no una meta efectiva para ella. ${ }^{(28)}$

La comunidad de la que habla Peirce debe interpretarse, según nuestro parecer, como un "nosotros" ético y político en el sentido hegeliano, no tan solo como el consenso racional entre los científicos, aunque en algunos pasajes de sus escritos Peirce solía

\footnotetext{
(26) Dotti, Jorge E., “El juicio como apriori epistemológico", Revista Latinoamericana de Filosofia, XVI, 3, Nov. 1990, p. 314.

(27) Peirce, C.S... “Algunas consecuencias de cuatro incapacidades“", p. 121.

(28) Kant se refiere explícitamente a la vida futura al explicar el "ideal del bien supremo". (The Critique of Pure Reason, trad. J.M.D. Meiklejohn, Great Books of the Western World, p. 238)
} 
realzar este aspecto. ${ }^{(29)} \mathrm{Su}$ acento en que el hombre individual "es sólo negación", por estar aparte del ser del prójimo y por manifestarse su existencia separada "por la ignorancia y el error" y, por otra parte, la relevancia dada a la noción de género humano como concepto práctico fundamental ${ }^{(30)}$, son elocuentes de la perspectiva antropológica y social de Peirce. Justamente, es este recurso a un consenso comunitario extracientífico el que ha hecho del pragmatismo de Peirce un antecedente de doctrinas críticas contemporáneas que, como en el caso de Apel y Habermas, presentan al conocimiento y a la acción en el contexto de una comunidad racional de comunicación.

No debe olvidarse, sin embargo, que Peirce creía que el método científico era la herramienta más apta para conducir este proceso comunitario de conocimiento, el medio capaz de controlar la falibilidad del mismo. A pesar de ello. Peirce era más "fundamentalista" que Kant. Así lo ha señalado James Liszka: el falibilismo de Peirce es parte de su gran cosmología acerca de la evolución del mundo y de la realización del absoluto, no por un desarrollo dialéctico, sino a través de la eliminación del error, en un sentido casi popperiano del progreso. ${ }^{(31)}$

La importancia que Peirce le otorgaba al método respondía a su idea de que la realidad no se patentiza en la mente sino por una rigurosa "purificación" lógica. Su critica al cartesianismo y al

\footnotetext{
(29) Es por ello que algunos intérpretes entienden que Peirce aludía a la comunidad de investigadores. V. por ejemplo. Potter, SJ, Vincent G.. "Peirce on "Substance" and 'Foundations'". The Monist. 75: 4. Oct. 1992. p. 500.

(30) Peirce, C.S.. "Algunas consecuencias de cuatro incapacidades". pp. 121/22: "Las obras de G.Berkeley". p. 87.

(31) Liszka. James J.. "Good and Bad Foundationalism: A Response to Nielsen". Transactions of the Charles S. Peirce Society. XXIX: 4. Fall 1993, pp. 574/75.
} 
método a priori se dirigía a mostrar que Descartes y sus seguidores no habían hecho más que consagrar los modos naturales de pensar: lo aceptable no es aquéllo que concuerda con la experiencia, sino lo que parece "agradable a la razón" y que ella inclina naturalmente a creer. ${ }^{(32)}$ A su vez, Kant presumía de realizar una crítica de estas inclinaciones, aunque, a juicio de Peirce. su método termina admitiendo las creencias generales y, por tanto, consolidando el elemento accidental y caprichoso de nuestro conocimiento. Para probarlo. Peirce señalaba en la $C R P$ una diferente argumentación para las nociones de espacio. tiempo y categorías, por un lado, y para las ideas como Dios. Libertad e Inmortalidad. por el otro. Kant habría admitido la creencia general en la existencia real de las cosas, aunque éstas contuvieran elementos que no aparecían a los sentidos, y en la universalidady necesidad de las proposiciones matemáticas, deduciendo de allí su pertenencia a nuestra naturaleza racional y, por ende. su aplicación a todos los objetos de la sensibilidad. ${ }^{(33)}$

Así, Peirce concluía que el método apriorístico, inclusive en su versión kantiana, había fracasado, pues sólo era confirmatorio de aquéllo que la mente ya estaba inclinada a pensar. ${ }^{(3+)}$ De acuerdo a su visión de la relación realidad-pensamiento, el método de la ciencia debía ser tal que las creencias no quedaran determinadas por ninguna circunstancia ajena a los hechos, "por algo humano, sino por algo permanente externo, por algo en lo que nuestro pensamiento no tenga efecto alguno “. ${ }^{(35)}$ Es la apelación a un sentido común crítico donde, por la concepción pública de la verdad

\footnotetext{
(32) Peirce, C.S.. "La fijjación de la creencia”. pp. 190/91.

(33) Ibídem. nota 18. pp. 191/92.

(34) Ibídem. pp. 193 y 196.

(35) Ibídem. p. 194.
} 
que Peirce profesaba, lo real es lo que tiende a influir en nosotros y no es extraño al pensamiento en general, aunque lo sea para un individuo. Por lo tanto, dicho método científico se asentaba sobre las siguientes hipótesis: a) existencia de cosas reales independientes de nuestras opiniones; b) afección de ellas a nuestros sentidos según leyes regulares de la percepción; c) a partir de dichas leyes, uso del razonamiento para averiguar cómo son verdaderamente las cosas; d) obtención, en última instancia, de una misma y única conclusión verdadera, que cualquier persona, con suficiente experiencia y raciocinio, puede alcanzar. ${ }^{(36)}$

En suma, Peirce se definía en favor del método empírico de la ciencia natural moderna como el camino para "fijar la creencia". En ese trance, el papel de la lógica consistía en "esclarecer las ideas", conduciendo el razonamiento sin la intención de hacerlo agradable a nuestros impulsos intelectuales, sino de evitar decepcionarse frente a los "hechos duros", que no se alterarían por más que nuestra opinión lo pretendiera. ${ }^{(37)}$

\section{III - Juicios y categorias}

Cuando Peirce afirmaba que el conocimiento constituye un proceso continuo, quería negar explícitamente que pudiera iniciarse por una intuición, aunque ella fuera sensible. Coincidía con Kant en que "la mente sólo puede transformar pero nunca originar conocimiento, a menos que se la alimente con los hechos de la observación" ${ }^{(38)}$, pero Peirce entendía a la experiencia como un

\footnotetext{
(36) Ibídem. pp. 194/95.

(37) Peirce, C.S., “¿Por qué estudiar lógica?”, p. 368; "Cómo esclarecer nuestras ideas”, p. 203 ; “La fijación de la creencia”, p. 196.
}

(38) Peirce, C.S., “Cómo esclarecer nuestras ideas”, p. 202. 
acontecimiento en un tiempo continuado. Así, la acción mental nunca estaba precedida por una cognición intuitiva, sino que se presentaba como un único movimiento lógico sometido a las leyes de la inferencia: "tenemos que reducir en la medida en que podamos, toda acción mental a la fórmula de un razonamiento válido sin ningún otro supuesto que el de que la mente razona". ${ }^{(39)}$ Peirce definía al pensamiento como "un hilo melódico que recorre la sucesión de nuestras sensaciones", ya que distinguía, por un lado, las sensaciones, como los elementos que siempre están presentes y de los cuales se tiene una conciencia inmediata, y por otro, el pensamiento como una acción con principio, desarrollo y fin, congruente con los datos sensibles y del cual tenemos una conciencia mediata. ${ }^{(40)}$

La diferencia sustancial entre ambos pensadores residía en el mecanismo por el cual la mente transformaba el material recibido. Kant anteponía a la actividad lógico-formal, los principios de la lógica trascendental, dando así prioridad a la síntesis respecto del análisis. Peirce, si bien estaba de acuerdo con Kant en que el conocimiento humano es discursivo y no intuitivo, confiaba en que la lógica general elevara las percepciones a conceptos mediante el análisis. Su cuestionamiento fundamental a la estructura cognoscitiva de la $C R P$ era que, en ésta, las representaciones aparecen separadas y son pensadas juntas a través de una síntesis mental, que es así lógicamente precedente. Para Peirce, "lo que realmente ocurre es que se presenta algo que en sí mismo no tiene partes, pero que, sin embargo, la mente lo analiza, es decir, que el que tenga partes consiste en esto, en que la mente reconoce después en él las partes". Cuando, separadas las ideas parciales, "pensamos en ellas, nos sen-

\footnotetext{
(39) Peirce, C.S.. "Algunas consecuencias de cuatro incapacidades". pp. 91 y 101.

(+1I) Peirce, C.S.. "Cómo esclarecer nuestras ideas". p. 206.
} 
timos llevados, a pesar nuestro, de un pensamiento a otro, y ahí reside la primera síntesis real. Una síntesis anterior a ésta es una ficción". (41)

Lo que importa discernir es que la lógica trascendental se proponía elevar a conceptos no las representaciones, sino la "síntesis pura" de las representaciones, el "enlace" de la diversidad sensible que sólo el entendimiento podía hacer. El análisis, también una facultad del entendimiento, suponía aquella composición sintética, pues no podría descomponer lo que no se hallaba ya ligado de algún modo. ${ }^{(+2)}$ Para Kant, la lógica general no necesitaba plantearse el origen de nuestros conocimientos, dado que hacía abstracción de toda materia de las representaciones y sólo se preocupaba por la coherencia interna del proceso analítico. La lógica trascendental, en cambio, no pretendía desechar el elemento sensible, sino partir de él, lo cual explicaba la necesidad de una síntesis previa de la diversidad. A su vez, el intento de Peirce era el de entender el proceso del conocimiento a partir de la lógica general, pero dando cuenta del contenido del mismo, sin necesidad de recurrir a formas a priori $o$, en otras palabras, restablecer la prioridad del análisis respecto de la síntesis. Veamos, en líneas generales, cómo Peirce llevaba a cabo esta suerte de inversión de Kant.

Peirce comenzaba por destacar en la experiencia el elemento de la "fuerza bruta", el hecho de que las cosas se nos imponen. No quedamos por ello obligados a sostener que es esa fuerza la que origina nuestro pensamiento, pero no podemos pensar más que a partir de ella. ${ }^{(43)}$ Ahora bien, eso que nos encontramos com-

\footnotetext{
(11) Peirce, C.S.. "Nota del editor proveniente de Collected Papers, 1.384”. pp. 398/99.

${ }^{(+2)}$ Kant, I.. Crítica de la Razón Pura. \# 10 y \# 15, pp. 176/77 y 206 y ss.

${ }^{(+3)}$ Peirce, C.S., “¿Por qué estudiar lógica?”. p. 338.
} 
pelidos a admitir produce ya un conocimiento directo, no una intuición sensible. En tal percepción inmediata, Peirce distinguía el "percepto" y los "hechos perceptuales". Percepto es aquéllo que se nos impone y que estamos forzados a aceptar sin crítica: la experiencia tal como es. Los hechos perceptuales son, en cambio, la descripción intelectual de aquella evidencia sensorial. Constituyen una memoria imperfecta y hasta, tal vez, infiel, de los perceptos, pero es el único registro con el cual cuenta la mente. No podemos criticarlo ni corregirlo, pues es imposible ir por detrás de él hacia los perceptos mismos. Los hechos perceptuales, aunque todavía involuntarios, son los datos originarios del razonamiento, momento éste en el que recién se hace posible el control a través de la lógica. ${ }^{(+1)}$

Para Peirce, pensar es esencialmente generalizar. Pero la mente nunca se encuentra con un singular, con el percepto. El primer juicio que podemos emitir sobre la realidad, el juicio perceptivo, ya implica algo de generalidad. Es la abstracción más inmediata. la primera forma proposicional sobre lo que no es una proposición, el percepto. Por tanto, aún siendo desigual a la realidad, el juicio perceptivo debe aceptarse como verdadero para ella. ${ }^{(45)}$ Contiene un mínimo de generalidad, pues es la forma lógica del hecho perceptual, que supone un recuerdo y un cierto enlace con experiencias pasadas. Si bien el juicio perceptivo no se deriva de premisa alguna, pues simplemente se impone a la mente, puede deducirse de él, por razonamiento necesario, una proposición universal. ${ }^{(46)}$

(4+) Ibídem. pp. 338 a 341.

(55) Peirce, C.S., "Nota del editor proveniente de Collected Papers, 5.568". p. 400.

(46) Peirce, C.S.. “¿Por qué estudiar lógica?”. p. 342: "Tres tipos de razonamiento”. (TR). p. 126. 
En concordancia con Kant, Peirce sostenía que nuestra sujeción a la experiencia está compensada por el hecho de que ella no es una compulsión ciega, ni nosotros somos totalmente extraños en el mundo. Lo que se nos da no está absolutamente determinado por la razón ni es completamente ajeno a ella. Pero a diferencia de Kant, Peirce creía que la síntesis categorial sólo podía tener lugar a posteriori. Así, un "elemento de razonabilidad", una cierta ley, se impone a las percepciones. Dicha ley no es una forma a priori ni deriva de ella, sino que es un "hábito de la razón". El proceso inferencial, quería decir Peirce, implica la formación de un hábito, pues produce una creencia en base a la cual un hombre está dispuesto a actuar. Estamos habituados a creer, "a sugerencia de ciertos hechos", que las ideas generales que obtenemos razonando se corresponden con una realidad. Si los perceptos escaparan a todo tipo de legalidad, "sería indiferente cuáles fuesen nuestras ideas generales". ${ }^{(47)}$

Por las características apuntadas, el juicio perceptivo de Peirce tiene virtud cognoscitiva, es ya una experiencia. El juicio de percepción kantiano, en cambio, tal como es presentado en los Prolegómenos, es una mera conexión de sensaciones para una conciencia particular sin referencia al objeto. Para que alcance validez universal y objetiva, es decir, para que tengamos experiencia, debe transformarse en juicio de experiencia por el enlace de los conceptos puros del entendimiento. Más aún, sin esa síntesis categorial, tal como aparece en la $C R P$, no puede haber juicio alguno, sino tan sólo representaciones ciegas. ${ }^{(48)}$

(+7) Ibídem, pp. 343 a 345 y 128.

(+8) Kant, I., Prolegómenos a toda metafisica futura que pueda presentarse como ciencia, \# 18 a \# 20, trad. Mario Caimi, Buenos Aires, Charcas, 1984, pp. 63 a 68 : Crítica de la Razón Pura, \# 15, pp. 206 y ss. Sobre este giro argumentativo y los riesgos que conlleva, puede verse Dotti, Jorge E., "La distinción kantiana entre juicios de percepción y de experiencia : problemas y sugestiones", Diálogos, 51, 1988, pp. 51 y ss. 
El modo de considerar la estructura intrínseca del conocimiento separaba nítidamente a Peirce de Kant. La tesis inicial de la $C R P$, según la cual se distinguíanjuicios analíticos y sintéticos, ya le merecía severos reparos. Para Peirce, la insistencia de Kant en "que el razonamiento necesario no hace más que explicar la significación de sus premisas", era totalmente equivocada, y su derivación hacia juicios explicativosy ampliativos era confusa e inutilizable. La objeción se basaba en los desarrollos de la lógica de relaciones, a la cual Peirce adhería, en el sentido de mostrar que los conceptos simples son, sin embargo, susceptibles de análisis. ${ }^{\left({ }^{(9)}\right)}$

Por otra parte, la conformación básica de la Estética Trascendental fue criticada también por Peirce. Una publicación reciente lo ha confirmado. Se trata de un manuscrito apenas posterior a sus lecciones en Harvard en 1865. En él, Peirce procuraba demostrar que el espacio y el tiempo no son intuiciones y pertenecen sólo parcialmente a la sensibilidad. Su argumentación cuestionaba que las sensaciones puedan elevarse por sí mismas a proposiciones sintéticas necesarias, por lo cual, espacio y tiempo deben ser, al menos en parte, conceptos intelectuales. Por otro lado, por la generalidad que implican y la necesidad de ser inferidos, espacio y tiempo no pueden ser representaciones singulares o concretas. ${ }^{(50)}$

Si para Peirce, el contenido total de la conciencia se infería de la experiencia, su critica al kantismo debía pasar por demostrar

\footnotetext{
(49) Peirce, C.S.. "Tres tipos de razonamiento“. pp. 139/40; Kant, I.. Crítica de la Razón Pura. Introd.. III y IV.pp. 66 y ss.

(5ii) Peirce, C.S. " [Hypotheses of Space and Time: A Response to Kant] Appendix $\mathrm{N}^{\circ}$ 2*. Transactions of the Charles S. Peirce Society. XXIX. 4. Fall 1993. pp. 645 a 669. Por la novedad del material, hemos tomado en cuenta las sugerencias del editor André De Tienne (“Editor’s Introduction“. en esp. pp. 637 a 642). Un análisis del manuscrito aludido, que muestra una réplica de tipo kantiano a las críticas de Peirce. puede verse en el mismo volumen Mitchell, S., "Peirce's Response to Kant in Appendix 2: A Contemporary Assessment”. pp. 675 y ss.
} 
cómo las formas categoriales podían dar cuenta de la realidad sensible. Además, el pensamiento no consistía para él en entrelazar conceptos, sino en algo más fundamental: combinar signos. De allí que para comprender la estructura intrínseca de nuestro conocimiento fuera preciso desarrollar una lógica semiótica. El "yo pienso" de Peirce es un "yo significo", pues no podemos pensar más que por signos. Pero este "yo pienso" no es trascendental; impone leyes de significación al pensar la realidad externa y conformarla como un mundo para él, pero al hacerlo, se construye a sí mismo. Es el "hombre-signo", que hace la palabra y ésta, a su vez, lo educa, pues es el único medio para interpretar su pensamiento. ${ }^{(51)}$

Ahora, todo nuestro mundo es un mundo de representaciones: "algo que se supone está por otro, y que puede expresar este otro a una mente que verdaderamente pueda entenderlo". ${ }^{(52)}$ Según Peirce, los modos bajo los cuales categorizamos esas representaciones provienen de la experiencia misma. No integran, por tanto, el ser de la realidad, como en Aristóteles, ni son conceptos puros a priori que conforman objetos de conocimiento, como en Kant. Surgen, en cambio, de un análisis de la experiencia concreta. Las categorías peircianas son las generalidades más fundamentales que se pueden aplicar a los fenómenos, los modos más abarcativos que en su uso habitual muestra la experiencia. Por tener este origen pragmático, están abiertas a nuevas categorías y, además, no pueden dar lugar a un conocimiento universal y necesario, sino probable, al menos, hasta que en la "opinión final", en la sumatoria de las experiencias, aparezca la verdad. En estricto sentido, pues, un es-

\footnotetext{
(51) Peirce, C.S., "Algunas consecuencias de cuatro incapacidades". pp. 120/21 y 100/ 01 .
}

(52) Peirce, C.S.. "Icono, Index y Símbolo". p. 142. 
quema categorial nunca está concluido y entraña un origen y un procedimiento social de continuo ajuste. ${ }^{(53)}$

Peirce consideraba que nuestra experiencia contiene fundamentalmente una estructura triádica. Por ello son tres las categorías universalmente presentes en todo fenómeno: las llamadas "primeridad", "segundidad" y "terceridad". Con la idea de primero, Peirce denotaba la percepción, la cualidad percibida por sí misma con exclusión de su pertenencia un objeto. Es, por tanto, sólo una posibilidad. Segundo es, en cambio, el "hecho duro": implica una reacción, un objeto en relación a otro en el mismo hecho. Es lo actual, lo que es ya. Como tercero aparece la mediación, el orden legal que implica al fenómeno y que establece una necesidad potencial, una probabilidad. El proceso continuo del pensar es básicamente una terceridad; la vida y la realidad en general son terceridad, pero un objeto determinado, o una específica realidad, son segundidad; el puro sentir y la idea de ser son primeridad. El pensamiento propiamente dicho, la cognición, es terceridad que contiene, sin embargo, a las otras categorías: lo primero como idea vaga, lo segundo como información. ${ }^{(54)}$

Peirce veía avanzar en "lo diverso de los sentidos" de Kant la noción de primeridad, mientras que en la unidad sintética predominaba la terceridad. Categorías como causalidad, existenciay otras representaban una segundidad. Desde su punto de vista, el análisis categorial de la $C R P$ era lúcido pero incompleto, pues "Kant no tenía la menor sospecha de la inagotable complejidad de la textura de los conceptos". Por ello, Peirce prefirió recuperar las tríadas

(53) Estos aspectos pueden verse en Lee, H.N., "A Semiotic-Pragmatic Theory of Categories“, The Southern J. of Philosophy, XXIV. 4, 1986, pp. 490 a 492.

(5) Peirce, C.S., “Tres tipos de razonamiento". pp. 128 a 130: "Casos degenerados“, (TR), pp. 163 a 168. 
hegelianas, aunque por un camino crítico, aquél que le permitiera restaurar el elemento de segundidad, el "hecho duro" que, a su juicio, no tenía un lugar adecuado en el sistema. ${ }^{(55)}$

Por distintas vías, Peirce y Kant han procurado justificar la validez del conocimiento científico y, en gran medida, el aporte de ambos ha sido decisivo para que entendamos hoy las bases filosóficas de su progreso. Kant señaló el camino de la crítica de las potencialidades de la razón en su teorización de la experiencia, a lo cual Peirce sumó un original análisis de la estructura lógico-semiótica con la cual pensamos. Constituyen dos interesantes muestras del modo en que la modernidad contempló la finitud del hombre en su capacidad cognoscitiva. La estructura falible del discurso científico, que Kant puso de manifiesto en la ilación entre la primera y la tercera Críticas, apareció luego en Peirce con una visión aún más débil de los universales, abiertos permanentemente a la complejidad del futuro. ${ }^{(56)}$ En ese terreno común dialogan sus filosofías.

(55) Peirce, C.S., "Tres tipos de razonamiento", p. 128: "Icono, Index y Símbolo". p. 142: "Casos degenerados", pp. 162, 167 y 171.

(56) Sobre la dimensión epistemológica del juicio reflexivo y su contribución a la apertura del discurso científico, ver Dotti, Jorge E.. "El juicio como apriori epistemológico". pp. 291 y ss. y "La razón en su uso regulativo y el a priori del 'sistema' en la primera Crítica", Revista de Filosofia, (Madrid. Univ. Complutense), 3a. época. I. 1987/88. pp. 83 y ss. 